\title{
Men had greater risk of recurrent venous thromboembolism than women
}

Kyrle PA, Minar E, Bialonczyk C, et al. The risk of recurrent venous thromboembolism in men and women. N Engl J Med 2004;350:2558-63.

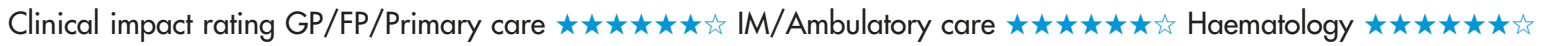

Does the risk of recurrent venous thromboembolism (VTE) differ between men and women?

\section{METHODS}

Design: inception cohort followed for a median of 26 months
(Austrian Study on Recurrent Venous Thromboembolism).
Patients: 826 patients $>18$ years of age (mean age 48 y, $55 \%$
women) who had a first episode of VTE and had been treated
with oral anticoagulants for $\geqslant 3$ months. Patients had received
standard heparin at doses designed to keep the activated partial
thromboplastin time $1.5-2.0$ times that of the control value or had
received subcutaneous low molecular weight heparin at
therapeutic doses. Exclusion criteria: surgery, trauma, or
pregnancy in the previous 3 months; known deficiency of
antithrombin, protein C, or protein S; lupus anticoagulant;
cancer; or need for long term treatment with antithrombotic
drugs. Women were discouraged from using oral contraceptives
or hormone therapy.
Prognostic factors: sex; age; presence or absence of
symptomatic pulmonary embolism at the time of first VTE;
duration of anticoagulation; and presence or absence of factor $V$
Leiden, factor II G20210A, and elevated concentrations of factors
VIII and IX.
Outcomes: recurrence of symptomatic VTE. The diagnosis of
deep venous thrombosis was confirmed by venography or colour
coded duplex sonography. The diagnosis of pulmonary embolism
was confirmed by ventilation perfusion lung scanning.

For correspondence: Dr P A Kyrle, Ludwig Boltzmann-Institut fü Thromboseforschung, Vienna, Austria. paul.kyrle@meduniwien.ac.at Sources of funding: Jubilaeumsfonds of the öster-reichische Nationalbank and Medizinisch-Wissenschaftlicher Fonds des Bürgermeisters der Bundeshauptstadt Wien.

Prognostic factors for recurrent venous thromboembolism*

\begin{tabular}{|c|c|}
\hline Prognostic factors & Relative risk $(95 \% \mathrm{Cl})$ \\
\hline Male sex ( $v$ female sex) & $3.6(2.3$ to 5.5$)$ \\
\hline Age (per 10 y increase) & $1.1(0.9$ to 1.3$) \dagger$ \\
\hline $\begin{array}{l}\text { Symptomatic pulmonary embolism } \\
\text { ( } v \text { deep venous thrombosis) }\end{array}$ & $1.7(1.1$ to 2.5$)$ \\
\hline Factor V Leiden ( $v$ absence) & $1.2(0.8$ to 1.8$) \dagger$ \\
\hline Factor II G20210A (v absence) & $2.1(1.1$ to 3.8$)$ \\
\hline $\begin{array}{l}\text { Factor VIII } \geq 234 \mathrm{IU} / \mathrm{dl} \\
(v<234 \mathrm{IU} / \mathrm{dl}[23.4 \mathrm{U} / \mathrm{I}])\end{array}$ & $2.9(1.6$ to 5.1$)$ \\
\hline $\begin{array}{l}\text { Factor IX } \geqslant 138 \mathrm{IU} / \mathrm{dl} \\
(v<138 \mathrm{IU} / \mathrm{dl}[13.8 \mathrm{U} / \mathrm{I}])\end{array}$ & $1.3(0.8$ to 2.0$) \dagger$ \\
\hline $\begin{array}{l}\text { Duration of anticoagulation } \\
\text { (per } 3 \text { mo increase) }\end{array}$ & $1.02(0.98$ to 1.05$) \dagger$ \\
\hline
\end{tabular}

*Relative risks were adjusted for age, presence or absence of a first symptomatic pulmonary embolism, factor V Leiden, factor II G20210A, elevated factor VIII or factor IX concentrations, and duration of anticoagulation. †Not significant.

\section{MAIN RESULTS}

102 patients (12\%) had recurrent VTE: 74 men $(73 \%)$ and 28 women $(27 \%)$. Men had a greater risk of recurrence than did women $(5 \mathrm{y}$ cumulative recurrence $30.7 \% v 8.5 \%$ ) (table). For men and women, risk of recurrent VTE was associated with an elevated concentration of factor VIII ( $\geqslant 234 \mathrm{IU} / \mathrm{dl}$ [23.4 U/l]), presence of factor II G20210A, and having symptomatic pulmonary embolism $v$ deep venous thrombosis as the first VTE event (table).

\section{CONCLUSION}

After a first episode of venous thromboembolism, men were at greater risk than women of a recurrent episode.

Abstract and commentary also appear in ACP Journal Club.

\section{Commentary}

yrle et al compared the incidence of recurrent VTE among men and women with incident unprovoked VTE (eg, no previous surgery or trauma) after a mean of 8-9 months of oral anticoagulant therapy. After excluding patients with high risk thrombophilic disorders (deficiencies of protein $C$, protein $S$, and antithrombin, or presence of lupus anticoagulant), they found that men with unprovoked VTE had $a>3$ fold higher incidence of recurrence than women. This result was surprising and unforeseen and did not appear to occur because women with unprovoked VTE taking oral contraceptives or hormone therapy simply stopped taking these hormones. In a stratified multivariate analysis, women with incident VTE who were not taking any hormones still had a 3 fold lower incidence of recurrent VTE than men.

Why do women have such a strikingly lower incidence of VTE when the incidence of first time VTE is the same between men and women? Possibilities include the following: (1) Men may not lyse a thrombus as readily as women, leading to more residual changes in the veins and a higher recurrence rate; (2) men might develop more comorbid conditions after the initial VTE event (eg, more hospital admissions or worse heart failure); and (3) men might have more underlying occult malignancies. The finding may also be due to chance or bias. This last possibility seems unlikely because another large study also found that women with unprovoked VTE had a significantly lower incidence of recurrent VTE than men (Baglin T. Personal communication), although this finding was not stated in the report of the study. ${ }^{1}$

A pressing need exists for prospective studies that more precisely define the risk factors associated with recurrent VTE, particularly among men and women with unprovoked VTE. The ultimate goal is to determine which patients receive more benefit than harm when prescribed long term anticoagulant therapy. Based on this study, it is still not clear exactly which women and which men are at such high risk of recurrent thromboembolism that they are appropriate candidates for extended anticoagulant treatment.

Richard H White, MD University of California, Davis Sacramento, California, USA

1 Baglin T, Luddington R, Brown $\mathrm{K}$, et al. Incidence of recurrent venous thromboembolism in relation to clinical and thrombophilic risk factors: prospective cohort study. Lancet 2003;362:523-6. 